\title{
Exceeding the Ontario Building Code for low-rise residential buildings: Economic and environmental implications
}

\author{
Adam M. Di Placido, Kim D. Pressnail, Marianne F. Touchie \\ Version Post-print/accepted manuscript \\ Citation Di Placido, Adam M., Pressnail, Kim D., Touchie, Marianne F. (2014). \\ (published version) Exceeding the Ontario Building Code for low-rise residential buildings: \\ Economic and environmental implications. Building and Environment 77, \\ pp. 40-49, doi: 10.1016/j.buildenv.2014.03.015. \\ Additional publisher The final version of this article is available from Elsevier at \\ information https://doi.org/10.1016/j.buildenv.2014.03.015 \\ Copyright/License \\ (c) (i) $\odot$ This work is licensed under the Creative Commons \\ International License. To view a copy of this license, visit \\ http://creativecommons.org/licenses/by-nc-nd/4.0/.
}

How to cite TSpace items

Always cite the published version, so the author(s) will receive recognition through services that track citation counts, e.g. Scopus. If you need to cite the page number of the author manuscript from TSpace because you cannot access the published version, then cite the TSpace version in addition to the published version using the permanent URI (handle) found on the record page.

This article was made openly accessible by $U$ of $T$ Faculty. Please tell us how this access benefits you. Your story matters. 
Exceeding the Ontario Building Code for Low-Rise Residential Buildings: Economic and Environmental Implications

Adam M. Di Placido (corresponding author), Department of Civil Engineering, University of Toronto

Kim D. Pressnail, Department of Civil Engineering, University of Toronto

Marianne F. Touchie, Department of Civil Engineering, University of Toronto

Corresponding author contact details: +16475006107, adam.diplacido@mail.utoronto.ca. Department of Civil

Engineering, University of Toronto, 35 St. George Street, Toronto, Ontario, Canada, M5S1A4

\section{Abstract:}

The residential sector accounts for approximately one fifth of Canada's secondary energy use and greenhouse gas emissions. Thus, addressing the energy efficiency of residential buildings has a significant role to play in reducing the nation's overall greenhouse gas emissions. The Ontario Building Code has recently been updated to reflect a more stringent energy performance standard. A home built to the prescribed minimum requirements will perform at a relatively high standard with respect to energy use when compared to homes built less than a decade ago. This paper explores three energy efficiency upgrade options which improve upon the energy efficiency of the 2012 Ontario Building Code. The "controlled ventilation" upgrade involved tightening up the building envelope and adding heat recovery to waste air streams, and two additional upgrade options were developed to meet the high performance targets of the R-2000 standard. While the upgrades explored did not show financial benefit for individual home owners at current utility rates, if the benefits to society are considered, the upgrades are an economically efficient method of reducing greenhouse gas emissions owed to energy consumption. In addition to highlighting the need for a broader approach to the cost-benefit analyses associated with these types of upgrades, this finding also warrants a discussion about how to transform the current housing market so that energy-efficient homes are more appropriately valued.

Key words: low-energy homes; Ontario Building Code; R-2000; greenhouse gas abatement; energy labeling; residential energy use; residential ventilation; energy efficiency economics 


\section{Introduction}

Climate change is one of the most pressing issues currently facing the global community. Climate scientists are largely in agreement that greenhouse gas (GHG) emissions are responsible for climate change and government bodies around the world are recognizing this and implementing measures to reduce their emissions. The Province of Ontario has summarized their emissions targets as well as plans to reduce atmospheric carbon in Ontario's Climate Change Action Plan [1]. Ontario's Climate Change Action Plan has set out targets to reduce GHG emissions to $15 \%$ below 1990 levels by 2020. Current investments in green energy, energy efficiency, and other programs are expected to bring Ontario $60 \%$ of the way towards the 2020 target [2]. In order for Ontario to reach the 2020 target, additional programs must be introduced across all sectors within the province.

The building sector is often cited as one of the most cost effective areas to reduce energy use and GHG emissions [3],[4]. With the vast majority of Ontario's building stock in the form of residential housing, there exists significant potential in the residential sector to reduce carbon emissions province-wide. The residential sector accounts for $17 \%$ of Canada's secondary energy use, $80 \%$ of which is used for space and domestic hot water (DHW) heating [5]. GHG emissions from Canadian homes are closely tied to energy use from the residential sector; $16 \%$ of the nation's carbon emissions are from residential buildings [5]. With the continued growth of the residential sector, new Ontario housing has an important role to play in meeting Ontario's future greenhouse gas emission targets.

Ontario is currently experiencing significant growth with over 65,000 housing starts estimated in 2012 [6]. The large number of housing starts in Ontario will lead to significant growth in the demand for energy use, which correlates with a growth in GHG emissions. While more homes will require more energy, the rapid development of communities within Ontario represents an immense opportunity for energy conservation. As these homes will be occupied for decades to come, we must evaluate how design decisions that we make today will perform in the future.

Ontario has been progressively improving energy efficiency requirements for new homes over the past several decades, where the most recent changes to the Ontario Building Code (OBC) have significantly improved the standard for the energy efficiency of housing starts in the province. The changes came into effect January $21^{\text {st }} 2012$, 
effectively improving home energy efficiency by $40 \%$ when compared to housing starts in 2006 [1]. The revised code requires homes that are occupied continuously over the winter months to have a performance rating of at least 80 on the EnerGuide rating system, which is a home energy performance rating system on a scale from 0 to 100 developed by Natural Resources Canada, or be in conformance with the prescriptive path for energy efficiency outlined in Supplementary Standard SB-12, Energy Efficiency for Housing of the OBC [7].

The prescriptive path for energy efficiency outlines several equivalent compliance packages for energy efficiency. Each compliance package bundles energy efficiency measures in the form of prescriptive requirements for the building envelope and mechanical equipment. These compliance packages were partially developed from the recommendations put forth in a report by Lio \& Associates [8] which were made on the basis of energy savings, GHG emissions, environmental impacts and costs, as well as barriers to adoption.

Since the implementation of the 2012 OBC, Dembo et al. [9] explored least-cost upgrade solutions that could be used to increase energy efficiency in new Canadian residential construction. A baseline model home was developed using the minimum energy efficiency requirements of the 2006 OBC which preceded the latest 2012 updates. From this baseline home located in Toronto, energy modeling was used to identify least-cost upgrade solutions. The least cost upgrades from the 2006 OBC included improved thermal resistance of the building envelope and installation of high efficiency HVAC equipment.

Most of the remaining literature on the reduction of energy-use and GHG emissions in the residential building sector focuses on improving the performance of existing homes through energy retrofits. Dowson et al. [10] reviewed the barriers to significantly reducing carbon related emissions by retrofitting the United Kingdom's (UK) existing housing stock. The major barriers identified included "hard-to-treat" solid walls, the large expense of replacing windows, and the high embodied energy in retrofit materials. Gamtessa [11] gave an overview of the residential energy efficiency retrofit behavior in Canada in conjunction with government incentives, and found that retrofits are more likely to be carried out in older less efficient homes, and that the likelihood of undertaking an energy retrofit was directly related to the expected cost savings and upfront financial incentives. Galvin [3] took a critical view of the generosity 
of Germany's financial incentives for single residential retrofits, citing the declining economic efficiency with more aggressive energy retrofits as the reason.

The focus of this paper is on the merits of energy efficiency in new construction. Building upon and updating the work previously mentioned by Dembo et al. [9], this study explores the economic and carbon implications of building more energy efficient homes than required by the 2012 OBC. To develop this case, a model of a typical single-family detached home that would just meet the energy efficiency requirements of the 2012 OBC was developed as the baseline. Three separate energy efficiency upgrade options were developed and modeled using home energy simulation software to compare both energy savings and carbon reductions. The most basic upgrade entailed tightening up the building envelope and adding heat recovery to the ventilation system. The two remaining upgrades included increased levels of insulation and high performance windows which meet the R-2000 energy target. R-2000 is a voluntary home performance standard administered by Natural Resources Canada, and is based on such metrics as energy efficiency, indoor air quality, and environmental responsibility. The R-2000 energy target was recently updated to reflect improvements in building codes across the country and subsequent advances of industry standards [12]. It is this updated target upon which the upgrade options have been based. The difference between the two R-2000 models was the fuel source used for space and water heating-the more typical model used natural gas for heating while the less carbon-intensive model was powered and heated exclusively by electricity. These measures showed more significant reductions in energy use and GHG emissions.

\section{The Model Homes}

To obtain energy simulation inputs, four model homes were developed that would be representative of new homes being built in Ontario in both size and fenestration ratios. The baseline model was generated based on the OBC and two of the three energy efficiency upgrade options were designed to qualify for R-2000 certification.

The overall dimensions and placement of windows and doors were held constant to enable a comparison amongst the baseline model and the different upgrades. These parameters were selected to best reflect the average new home being built in Ontario. The average home size of a new single detached home in Ontario is 177 square meters [6]. The model home was designed to capture this with a square building footprint measuring 10 meters by 10 meters 
over two stories. The model includes a basement which extends 1.86 meters below ground. The Canadian SingleDetached and Double/Row Housing Database (CSDDRD) was consulted in selecting window-to-wall ratios for accurate representation of newly constructed homes; the average glazing area of homes built since the 1980s has remained steady at about $15 \%$ of the wall area, and the average south facing window area is currently about $5 \%$ of the conditioned floor space area [13]. Using these glazing ratios as a guide, all four models include $6.7 \mathrm{~m}^{2}$ of windows on each of the north, west, and east elevations, and $10 \mathrm{~m}^{2}$ on the south elevation. Two doors were placed on ground level with a thermal resistance value of $0.7 \mathrm{~m}^{2} \mathrm{~K} / \mathrm{W}$, corresponding to $\mathrm{R} 4\left(\mathrm{ft}^{2{ }^{\circ}} \mathrm{Fhr} / \mathrm{Btu}\right)$.

The baseline model home was designed using the prescriptive path of the OBC [7]. Three upgraded models were developed using widely available technologies and building materials as well as common construction practices within Ontario so that the upgrades would be representative of a housing archetype that could be adopted with ease across the province. The first upgraded model home was developed by upgrading the standard OBC home by improving the ventilation through a tighter building envelope and a heat recovery ventilator (HRV) unit. The second upgraded model home was created by upgrading to the new R-2000 standard. The third upgraded model was also designed to the R-2000 standard, but natural gas-fueled appliances were eliminated and the home was powered exclusively by electricity. Model Inputs are summarized in Table 1.

All computer model simulations were performed with the standard values for home occupancy, internal loads, temperature set points, DHW use, and other site conditions outlined in the 2012 R-2000 Standard, Appendix B [12]. Simulations were performed using the Toronto weather file, which would be applicable for the majority of housing starts in the province. Figure 1 shows the monthly average outdoor temperatures from the weather file used with HOT2000 for reference of the Toronto climate. The four model homes are discussed below.

\section{Model I-The Standard OBC Home}

The prescriptive path for building code compliance laid out by SB-12 was used in developing the OBC home model. Component U-values and HVAC efficiencies were selected in accordance with Compliance Package C for Climate Zone 1, which includes most of Southern Ontario. To achieve the required $4.75 \mathrm{~m}^{2} \mathrm{~K} / \mathrm{W}$ (R27) wall insulation, a $5 \mathrm{~cm}$ by $15 \mathrm{~cm}$ ( 2 by 6 inch) wood frame wall construction with glass-fibre batt in the cavities and $5.1 \mathrm{~cm}\left(2^{\prime \prime}\right)$ of extruded 
polystyrene (XPS) rigid board insulating sheathing was assumed. $38.1 \mathrm{~cm}\left(15^{\prime \prime}\right)$ of blown-in cellulose insulation was used in the attic to achieve $8.81 \mathrm{~m}^{2} \mathrm{~K} / \mathrm{W}$ (R50) ceilings. The basement was insulated from the interior with glass-fibre batt in a wood stud wall for an overall $2.51 \mathrm{~m}^{2} \mathrm{~K} / \mathrm{W}$ (R14). The basement was also insulated from the exterior with $2.54 \mathrm{~cm}\left(1^{\prime \prime}\right)$ of XPS board insulation extending 0.6 meters (2') below grade. Double-glazed windows with lowemissivity coating and argon gas fill were selected to conform to the maximum prescribed window $\mathrm{U}$-value of 1.8 $\mathrm{W} / \mathrm{m}^{2} \mathrm{~K}[7]$. These windows had a solar heat gain coefficient (SHGC) of 0.56 . Natural infiltration was set to 2.5 air changes per hour at a 50 Pa pressure differential $\left(\mathrm{ACH}_{50}\right)$ as assumed by SB-12 for energy modelling purposes [7]. This is just less than the average observed by Harris [14] of $2.82 \mathrm{ACH}_{50}$ for new Ontario housing in 2009, and is thus likely a conservative estimate. See Figure 2a) for the envelope cross-section of Model I.

\section{Model II-The OBC Home with Controlled Ventilation}

The basic upgrade from the $\mathrm{OBC}$ home included heat recovery through a HRV unit with an assumed efficiency of $65 \%$ in heating and $20 \%$ in cooling, which agrees with HRV performance averages calculated from the Home Ventilating Institute (HVI) product database [15]. The assumed HRV power consumption was $130 \mathrm{~W}$, derived by averaging the power consumption and flow rate from the same database. The natural air infiltration was also reduced from 2.5 to 1.5 $\mathrm{ACH}_{50}$, in line with the envelope tightness target set out by the R-2000 standard. This can be accomplished through greater quality assurance, particularly by paying greater attention to the continuity of the air barrier at perforations through the building envelope, such as at windows, doorways, and vents. See Figure 2a) for the envelope cross-section of Model II.

\section{Model III-The R-2000 Home (Fuel-Fired)}

To reach the energy target set out by the R-2000 program, the total thickness of XPS insulation on exterior walls was increased to $10.2 \mathrm{~cm}\left(4^{\prime \prime}\right)$, extending $0.6 \mathrm{~m}$ below grade. For above grade walls this results in a total nominal resistance of $6.6 \mathrm{~m}^{2} \mathrm{~K} / \mathrm{W}$ (R37). Interior basement insulation was increased with $5.1 \mathrm{~cm}\left(2^{\prime \prime}\right)$ of XPS rigid board insulation (R10) for the full height. Attic insulation was increased to a nominal thermal resistance of $11.66 \mathrm{~m}^{2} \mathrm{~K} / \mathrm{W}$ (R66) by adding an additional $11.4 \mathrm{~cm}\left(4.5^{\prime \prime}\right)$ of blown-in cellulose insulation. Windows were upgraded to krypton filled units with two suspended heat reflective films resulting in a centre of glass thermal resistance of $2.12 \mathrm{~m}^{2} \mathrm{~K} / \mathrm{W}$ 
(R12) and SHGC of 0.30. The 40-gallon natural gas-fueled water heater was replaced with an instantaneous (tankless) natural gas water heater to reduce domestic hot water energy consumption. See Figure $2 b$ ) for the building envelope cross-section of Model III.

\section{Model IV-The R-2000 Home (Electric-Powered)}

To electrify the home, the natural gas furnace and central air conditioning unit were replaced with a single air-source heat pump with electric resistance backup heating. The heat pump was assumed to have a Heating Seasonal Performance Factor (HSPF) of 8.5 and Seasonal Energy Efficiency Ratio (SEER) of 15, representative of high efficiency units for the Toronto climate [16]. The natural gas-fueled instantaneous water heater was replaced with a 40 gallon electric tank. See Figure $2 b$ ) for the building envelope cross-section of Model IV.

\section{Computer Simulation}

The low-rise residential housing energy simulation software, HOT2000 Version 10.51 [17], was used to model the energy performance of the four model homes including the $\mathrm{OBC}$ baseline and three upgraded options developed for this study. HOT2000 was developed by Natural Resources Canada as a means to evaluate home energy performance for various government incentive programs, to inform policy, and for evaluation against government rating systems such as EnergGuide and the R-2000 standard.

HOT2000 simulation results revealed that the OBC Home had an annual space and domestic hot water heating requirement of 78 equivalent kilowatt hours (ekWh) of natural gas per square meter of habitable floor area. Figure 3 shows the breakdown of annual heat losses through various home components. Of the avenues for heat loss, ventilation represents the largest portion of annual heat loss at $40 \%$. Consequently, addressing ventilation losses can be the most impactful measure from the perspective of the building fabric when reducing home heating energy use. This was also one of the key recommendations made by Lio \& Associates towards the Ontario Ministry of Municipal Affairs and Housing back in 2006 in their study of energy efficiency measures for low-rise housing [8].

Figure 4 displays the energy required for both space heating and domestic hot water use for the four homes modeled. By simply tightening up the building envelope and installing an HRV, $27 \%$ reductions in heating energy 
over the OBC home were realized. The implications of such energy reductions from simple changes in home construction are fairly significant for home starts in 2017 -the OBC is requiring homes built after December 31 st 2016 to be $15 \%$ more energy efficient than the current requirement. A $15 \%$ improvement in efficiency can easily be met with greater attention to the continuity of the air barrier and implementing heat recovery from waste air streams.

After improving ventilation, the windows, walls and the basement are the greatest sources of annual home heat loss. With added insulation, which is relatively inexpensive at the construction phase, and installing higher performance windows, space heating requirements are reduced by over half. This reduction can be seen in Figure 4 by comparing the space heating energy use of the OBC home with controlled ventilation and the fuel-fired R-2000 home. Upgrading the water heater to an instantaneous unit significantly reduces standby DHW losses over the cooling season. As such, the fuel-fired R-2000 home resulted in 55\% reductions in heating energy over the baseline OBC home. The electrically-heated R-2000 home with a high-efficiency air-source heat pump resulted in a $70 \%$ reduction in heating energy over the standard $\mathrm{OBC}$ home.

\section{Economics of Building Better Homes}

To evaluate the economic opportunity for homeowners of building better than the OBC, the estimated incremental costs of each of the three upgrade options was compared with the total energy savings based on current utility rates. The construction costs associated with the energy efficiency upgrades were estimated through industry standards and consultation with suppliers and installers. Tables 2, 3, and 4 show the breakdown of estimated upgrade costs over the standard OBC home.

Upgrade costs for the three models were then amortized over a 25 -year mortgage to determine the incremental mortgage payment the homeowner would be responsible for annually. A $5 \%$ fixed mortgage rate was assumed for determining annual payments. It should be noted that the following ecuılomic analysis does not take into account the effect a carbon tax would have on future cash flows, nor the increase in capital value of the home due to energy efficient or "green" labeling - with no widely received home energy efficiency rating system currently adopted, the increase in property value from lower operating costs and the energy efficiency label would not likely be reflected 
in the current marketplace to a significant degree. Recommendations for a mandatory home energy rating system are discussed in Section 6. Table 5 shows estimated annual energy costs of the four homes modeled, as well as the energy savings and incremental mortgage payments over the OBC home.

As shown in Table 5, none of the energy efficiency upgrade options modeled will provide a return at present utility rates, although the energy cost savings of the controlled ventilation model is only $\$ 18$ short of covering the incremental mortgage payment. The electric-powered R-2000 home costs more to operate than the standard OBC home despite much lower energy requirements due to the price difference between natural gas and electricity.

To determine which of the individual upgrades would provide a positive financial return, each upgrade was added individually to the base case model. The independent return on investment (ROI) of each of the individual upgrades was then determined and presented in Table 6 to compare individual returns. Reducing the natural infiltration was the only measure that provided a positive ROI at present utility rates. Despite having the highest initial cost of upgrade, the high performance windows proved to be one of the better investments of the upgrades that did not provide a return. This was because decreasing the SHGC of the windows was the only measure that also significantly lowered electricity costs, which sells for a higher rate than natural gas. The impact of the substantial price difference between natural gas and electricity on upgrade economics is particularly evident with the HRV; despite significant savings in natural gas, the resulting increase in electricity expenditure from the additional HRV fan power diminished cost savings. None of the insulation upgrades provided favorable returns due to the high levels of insulation in the base case and the inverse relationship between conduction and thermal resistance.

In order to perform a fair evaluation of the economic returns, the financial model must consider the whole 25 -year mortgage term, and thus forecast future utility rates.

Ontario Hydro electricity prices are expected to rise between $46 \%$ and $58 \%$ for residential customers over the next five years [18]. Natural gas price projections were obtained from the early release of the 2013 energy outlook prepared by the U.S. Energy Information Administration (EIA). Natural gas prices, although historically have been very volatile, are expected to hold relatively constant over the next several years [19]. These estimates were based on continued shale gas expansion in the North American market, continued high crude oil prices and improved 
drilling efficiencies. After 2018, the price of natural gas is expected to rise annually at a rate of $2.5 \%$ until 2030 , and then by $3.7 \%$ until 2040 in 2011 dollars as demand increases and natural gas in remaining reserves becomes more difficult to extract [19].

Over the next five years, financial models developed for this study assumed natural gas rates would rise with inflation (assumed to be 1\%) and electricity rates were assumed to rise uniformly by $50 \%$ over this same period. Utility rate projections over the next five years were thought to be predicted with high confidence, so only this single utility rate escalation scenario was considered. Projecting rates after this period posed difficult with no long-term forecasts of Ontario's electrical rates, and the uncertainty that arises in the long-term natural gas price projections provided earlier.

A sensitivity analysis was performed on the utility escalation rate after the five-year mark by developing an upper and lower bound escalation scenario. The upper and lower limits of the electricity escalation rates ranged between $2 \%$ and $9 \%$; the lower bound assumes modest increases after the rapid escalation predicted over the next 5 years, while the upper bound assumes electrical rates will roughly continue on their current predicted trajectory. The lower bound natural gas escalation rate was in line with the forecast provided by the EIA. The upper bound natural gas escalation scenario assumed a $1 \%$ increase over the over the EIA projections where prices would begin to escalate by $3.5 \%$ over inflation in 2015 until 2030, after which, the escalation rate was assumed to increase to $4 \%$ over inflation.

After developing the upper and lower bounds of utility escalation scenarios, a third escalation scenario was developed that provided a representative average between the upper and lower bounds. This average scenario was then adjusted for both climatic changes in Southern Ontario and rising mortgage rates. The higher mortgage rate scenario assumed that mortgage rates would increase from $5 \%$ to $6 \%$. The intention of the climatic adjustment is to account for a weather year warmer than the average historical weather year used by HOT2000.

HOT2000 uses a weather file for Toronto that includes 3650 heading degree days (HDD). As the effects of climate change will likely reduce the number of HDD in the future, part of the sensitivity analysis includes accounting for this decrease. In 2012, the City of Toronto recorded only 3100 HDD. Although this was a particularly warm year, it could 
be indicative of future weather patterns in the region. As such, the natural gas savings were adjusted by a factor of 0.85 to scale down the heating energy requirement from that generated by the weather file used by HOT2000. The factor of 0.85 was determined based on the ratio between the HDD for the City of Toronto in 2012 and the number of HDD in the HOT2000 Toronto weather file [20]. This method of adjustment is reasonable because the relationship between heating degree days and heating energy use is approximately linear.

Validation of this concept has been performed by the authors by comparing predicted heating energy use of buildings through computer simulations by using both a standard weather year (CWEC) and a weather file from a warmer year [21]. By adjusting the weather-related natural gas consumption from the standard weather year model by an appropriate Heating Climate Index $(\mathrm{HCl})$, which was generated much the same way as the natural gas adjustment factor used here, the estimated heating energy intensities were very similar to running the computer simulation with an updated weather file.

The global adjustment of 0.85 was applied to the total natural gas used. While 0.85 would be an over adjustment of the natural gas used for DHW, warmer air temperatures would also undoubtedly increase the water main temperatures and thus decrease water heater energy use.

The net annual cash flows of the OBC home with controlled ventilation and the fuel-fired R-2000 home are shown in Figures 5 and 6 respectively. A financial model of the electric-powered R-2000 home was not included because the energy utilities at current rates are greater than the utilities for the standard OBC home. The model with controlled ventilation is very sensitive to the cost of electricity due to the increase in electricity required to power the HRV. Despite significant savings in natural gas, increased electricity costs dominate financially due to the relative price between electricity and natural gas and the projected growth in the price gap between the two energy sources over the next five years. After this period, it is only with modest escalation in electricity prices that the cash flows become positive over the mortgage term. While high escalation of electrical utility costs degrade financial returns for the OBC home with controlled ventilation, rising electricity rates improve the economics of the fuel-fired R-2000 home because the reduction in electricity use from lower cooling requirements more than offset the increase in 
electricity needed to power the HRV. Both models showed great sensitivity to climatic changes and the mortgage rate, however, for the $\mathrm{OBC}$ home with controlled ventilation, electricity rates were the dominating factor.

A few of the financial models showed a favorable financial return over the 25 year mortgage term. While this does not make the financial case for the homeowner alone, these models can be used to show the true net benefit or cost over the lifecycle of the upgrades. The net present value (NPV) was calculated for each financial scenario using equation (1), where the energy savings in any given year are calculated assuming $1 \%$ inflation in addition to the fuel cost escalation, and net cash flows are discounted to the present at a rate of $2 \%$. The NPV of the controlled ventilation model ranged from $-\$ 1,215$ to $+\$ 104$ and the NPV of the fuel-fired $R-2000$ home ranged from $-\$ 1,633$ to $+\$ 1,867$, depending on the financial assumptions. With greater home buyer education through the introduction of mandatory energy labeling, which is discussed in Section 6, the likelihood of the owner recouping these relatively small NPV "deficits" is much greater.

$N P V=\sum_{t=1}^{25} \frac{\text { Energy Savings in Year t-Incremental Mortgage Payment }}{(1+0.02)^{t}}$

This section has explored the economic benefit to the homeowner directly. The broader economic benefits to society in terms of avoided energy generation and expansion of associated energy generation infrastructure are discussed in the context of carbon emission reductions in Section 5. The NPV ranges presented in Section 4 were then used to assign a time averaged cost of abatement for GHG emissions per tonne of carbon dioxide. Similarly, this method could also be used to assign costs to other intangible benefits of low-energy homes such as improved occupant comfort and reduced exposure to risk from energy prices and supply disruptions.

\section{Carbon Implications of Building Better Homes}

An estimate of the carbon emissions from the four home models was determined using HOT2000 simulation results. The emissions factor used for natural gas consumption was $1.879 \mathrm{~kg} / \mathrm{m}^{3}$ and $0.11 \mathrm{~kg} / \mathrm{kWh}$ for electricity based on Ontario's electric grid average [22]. Figure 7 displays the annual GHG emissions derived from natural gas and electricity normalized as tonnes of carbon dioxide equivalent ( $\left.\mathrm{tCO}_{2} \mathrm{e}\right)$ for the four homes modeled. 
The difference in carbon emissions between the $\mathrm{OBC}$ home and each of the upgrades represents the magnitude of abated carbon as a result of the upgrade. The cost of GHG abatement was estimated based on the net cash flows from the baseline financial models presented in Section 4. Table 7 shows the estimated cost of abatement per $\mathrm{tCO}_{2} \mathrm{e}$ at present utility rates as well as over a 25-year period. In estimating the cost of abatement over a 25 -year period, the average NPV of the three upgrade options was used from the financial scenarios presented earlier. This total net cost was then divided by the total predicted $\mathrm{tCO}_{2} \mathrm{e}$ abated over the same 25 -year period. The home built to the $\mathrm{OBC}$ with controlled ventilation resulted in the cheapest cost of abatement at present and when averaged over a 25 -year period. Due to the high projected cost of electricity relative to natural gas, the R-2000 electrically heated home is the most expensive means of carbon abatement of the three upgrade options explored, despite resulting in the lowest overall emissions. It was also the only option that showed increased abatement costs when projecting into the future due to the rapidly escalating cost of electricity.

The cost of abatement shown here can be used as a measure of the economic efficiency of carbon reduction through constructing new homes to more stringent energy standards than required by code. The trend shown here for new homes is similar to trends noted in empirical studies of home retrofit economics where more intensive energy efficiency measures show a less favorable economic efficiency [3], adhering to a law of diminishing returns. Thus, it is usually more economical to retrofit homes with poor energy performance, than to retrofit a home that is already energy efficient. The same can be said when benchmarking energy efficiency upgrades for a new home against a fairly well performing standard, such as that set by the OBC. An important distinction between new builds and existing homes is the relative cost of improving energy efficiency; while replacement of HVAC equipment is usually on par with the initial installation cost, the initial cost of envelope upgrades for new construction is comparatively less expensive than envelope retrofits of existing homes. Therein lies the logic of building to the highest practical standards during the initial construction.

While the cost of abatement is an important metric in determining the viability of home energy efficiency upgrades, so too is the impact that these measures will have on the province's overall carbon emissions. Based on current initiatives, the projected gap in GHG emissions from Ontario's Climate Change Action Plan 2020 target will be 38 Mt $\mathrm{CO}_{2} \mathrm{e}$ [23]. The total annual carbon emissions in the year 2020 from all future homes starts were estimated for each 
of the НОT2000 home models if built exclusively from today onwards, with the standard OBC home representing the "business-as-usual" case. Total annual emissions estimated for 2020 were based on 65,000 housing starts per year from 2013 to 2020, and the business-as-usual case took into account the planned $15 \%$ energy reductions in 2016 by the OBC.

Based on abated emissions, the relative contribution of building better than the OBC today will have towards closing the carbon reduction gap and achieving Ontario's 2020 targets was estimated as a percentage, shown in Table 8. While simply adding heat recovery and improved envelope tightness to the current OBC is the cheapest form of carbon abatement, upgrading to the R-2000 standard results in more significant contributions to reducing Ontario's carbon emissions; If all homes built from today onwards were designed to the R-2000 standard, the 2020 target gap could be closed by between $3 \%$ and $4.5 \%$, when compared to just less than $1 \%$ if only ventilation improvements were undertaken with the current code.

While building to the R-2000 standard will provide significant reductions in residential carbon emissions over the minimum requirements of the OBC, the greatest potential for GHG reductions in Ontario's housing sector lies with energy retrofits of existing buildings. As of the 2011 census, there were 4.8 million private dwellings in the province of Ontario, 2.7 million of which were single-detached homes [24]. Most existing homes were built to much less stringent standards than the current building code dictates; as recently as 2006 the building code was $40 \%$ less energy efficient than it is today. Quantifying the potential for carbon reductions from the existing housing stock, as well as the cost of doing so, is outside the scope of this study, but these statistics speak to the relative contribution energy retrofitting can have towards reducing Ontario's GHG emissions. There are however challenges with implementing retrofits on a wide scale; differing vintages and housing types affect retrofit limitations, costs, and potential savings, and there also exists barriers to accessing and retrofitting low-income and affordable housing for retrofit. These limitations help highlight the benefit of building better initially, when minimum energy efficiency standards are more easily enforced and installation costs are much lower. 


\section{Recommendations}

The recent revisions to the building code have established Ontario as a North American leader in energy efficient homes. The $\mathrm{OBC}$ has set the minimum standard high enough that most of the "low-hanging fruit" of energy saving upgrades at the construction phase have been addressed. When looking at today's energy prices, it is difficult to justify further improvements in efficiency based on the economic benefit to individual homeowners alone. Even with energy price forecasts based on the best data available, it is hard to justify all but the most basic improvements from this perspective. What the analysis of economic benefit to the homeowner fails to capture however, are the intangibles such as improved occupant comfort and home durability, resilience to rising energy costs and supply, and a lesser impact on the environment.

What this shows is a need to address market failures - the benefits of energy efficiency are simply not valued in today's housing market, nor is the scope of an economic analysis large enough to extend much beyond the individual homeowner. What is needed is new policy to drive market transformation to more appropriately value low-energy homes for both new construction and existing homes. In order for the residential sector to fully partake in Ontario's Climate Action Plan, a concentrated effort is needed in incentivizing energy efficient retrofits targeted at poor performing homes, and to push new construction to outperform the minimum requirements of the current code. These efforts represent a cost-effective way to reduce emissions compared with many other mitigation strategies [4]. Recommendations are described below.

\section{Mandatory Energy Performance Certificates}

One method of addressing this market failure gaining traction globally, particularly in Europe, are mandatory Energy Performance Certificates (EPC). The EPC introduces a new level of transparency in the housing sector by providing the homebuyer with relevant information on energy performance and associated costs, which is otherwise not provided. This then allows for direct comparison between different homes on the market so that the energy performance can then be better reflected in the sale value of the home. In the case of new construction, this would allow developers to more easily recuperate upgrade costs, and in the case of resale homes, allow the existing homeowner to more easily recuperate retrofit costs. 
Home energy efficiency labeling is voluntary under most North American jurisdictions. The European Union (EU) has introduced the Energy Performance of Buildings Directive, which requires EPCs be made available when new buildings are constructed, sold or rented in the EU [25]. Australia also requires energy use disclosure when transferring ownership of homes [26]. While the EnerGuide rating system and R-2000 certification have similar objectives to the EU's EPC directive, they do not currently have the same market penetration due to their voluntary participation. Provisions for the mandatory disclosure of energy performance upon the change in ownership of a home on the other hand, would have a much greater impact on the overall energy use of newly constructed and existing homes in the Province.

Lawrence Berkeley National Laboratory performed a literature review of studies quantifying the added value of EPCs and other "green" building labels such as the ENERGY STAR label. Three studies were reviewed specific to the economics of energy labels in the American, Dutch and Australian housing markets; all three studies found a positive correlation between energy labels and home selling price. Price premiums ranged from 1 to $10 \%$ depending on the energy rating presented on the EPC label [26].

The United Kingdom has followed suit with the rest of the EU in mandating EPCs for homes being built, sold or rented. A recent consumer survey found homebuyers were not very receptive to the rating and information provided on EPCs and that the EPC had little to do with home purchasing decisions [27]. The average homebuyer perceived the EPC as too technical and felt overwhelmed with the amount information presented. There was also some mistrust in the information presented in the EPC from not fully understanding the methods used to derive the information.

Ontario could learn from the successes and failures of mandatory EPCs in Europe and the UK. Recommendations from the UK consumer survey included a simplified certificate provided to the homeowner with energy use presented in monetary values rather than $\mathrm{kWh}$ and $\mathrm{CO}_{2}$, since the latter has little meaning to the average homebuyer [27]. A simple rating system was also deemed to be important for quick comparison between homes. The A-G letter rating system, which is used extensively throughout Europe, was well received, as was a simple star system which is a common consumer rating system [28]. More technical information could then be made available for policy makers, 
researchers and informed homebuyers on request. Another issue encountered has been the discrepancy between calculated and actual savings from evaluations both due the prebound effect, where the measured consumption is less than the initial calculated value, and the rebound effect, where measured post-retrofit consumption is greater than anticipated [29]. The rebound effect is commonly attributed to higher occupancy comfort standards that can be afforded after a low-energy retrofit reduces the cost of heating and cooling [30].

\section{Preferential Mortgage Rates}

When considering the financial models, it was shown that financial returns are highly sensitive to the cost of money borrowed. Lending institutions are increasingly offering "green mortgages" to homeowners at lower interest rates for investments in energy efficiency. Two such programs were identified at the time of writing in the province of Ontario-the Canada Mortgage and Housing Corporation's (CMHC) Green Home insurance mortgage rebate program [31], and the Bank of Montreal's (BMO) Eco Smart Mortgage ${ }^{\mathrm{TM}}$ [32]. The rationale behind these preferential loans is that with lower home operating costs, the homeowner is more likely to be able to make mortgage payments, taking some of the risk off of lenders. Financing strategies such as this can improve energy upgrade economics and help safeguard homeowners against rising mortgage rates. A mandatory EPC would help to increase the success of green mortgages since such programs usually require third party appraisal through home energy audits. Mandatory EPCs would thus significantly simplify the application process as most homeowners would already have their energy performance known and on hand.

\section{Energy Conservation Initiatives}

The financial models also showed that even when energy requirements were drastically reduced, the associated savings for individual homeowners were not great enough to justify the initial upgrade. Shifting government funding and subsidies from the supply side of energy production and distribution to conservation would help provide the necessary market push for higher energy efficiency in homes and represent a cost-effective way for government to reduce emissions. The federal government's EcoENERGY Home Retrofit Program provided up to $\$ 5,000$ in grants towards energy efficiency upgrades but this program was discontinued as of January 21st, 2012 [33]. As government subsidies were found to play an important role in energy efficient retrofits, especially in low-income households 
[11], the renewal of this program would continue to encourage homeowners to perform home retrofits to improve upon energy efficiency. A similar program targeted at new construction could provide the financial incentives needed to encourage home builders to exceed the OBC. In order to maximize GHG reductions given limited financial resources, as noted by Galvin [3] in his analysis of Germany's retrofit subsidies program, the merits of such a program need to be analyzed to ensure that any funding dedicated to the program would be used in the most economically efficient manner. As with the green mortgages, the mandatory EPC would be a great starting point for such a program because the energy audit portion of the grant application would already be complete after an EPC directive had been phased in.

\section{Carbon Tax}

A carbon tax is another policy tool that can push the market towards conservation and energy efficiency. A carbon tax would assign a material cost to emitted GHGs, thus introducing an additional positive cash flow from abated carbon. It would also work to narrow the gap between the cost of electricity and more carbon intensive natural gas, improving the economics of electricity-powered efficiency measures such as HRVs and heat pumps. A carbon tax can be more easily sold to the Ontario public if it is revenue-neutral so that revenue from carbon taxation would allow for tax cuts from personal income, investment and small business.

There are fears that a carbon tax will hinder the continued growth and prosperity of Ontario's economy. However, empirical evidence from industrialized nations which have implemented a carbon tax or other form of environmental pricing seems to suggest otherwise. A review of the economies before and after the introduction of a carbon tax in Denmark, Sweden, Finland, the United Kingdom, the Netherlands and Germany found that all countries experienced modest economic gains after the taxing reform, except for the United Kingdom, which experienced neutral growth in their economy [34]. Politically closer to Ontario, the province of British Columbia introduced carbon pricing in 2008. Since the introduction of carbon pricing, the economic growth within the province of British Columbia has outpaced that of the rest of the nation [35]. 


\section{Conclusion}

Our homes are built for long-term occupancy and it is the responsibility of architects, contractors and engineers to design and plan for the entire lifecycle of the home. While designing for the future will inevitably introduce greater levels of uncertainty in any analysis, it is still an important exercise in helping to determine what the future will hold for today's design decisions. This is why the economics in this study were forecasted over a 25 -year horizon. The standard $\mathrm{OBC}$ model home was already a relatively high performing home. Because of this and current policy and energy pricing, only the $\mathrm{OBC}$ model with controlled ventilation could offer a positive financial return for homeowners depending on future utility prices. However, there were many intangible benefits to society that were excluded from this economic analysis, and these results should not preclude building our homes to higher energy standards. Building better now will inevitably create more resilient homes, safeguarding homeowners against volatile energy prices, improve comfort and reduce GHG emission in a cost-effective manner. And while the current code has significantly reduced energy use and GHG emissions from Ontario's new residential construction, it is important to continue to drive the construction industry forward and improve upon current practice.

While the focus was on new construction, retrofits of existing homes were also identified as a valuable recourse for allowing Ontario to meet its future emissions targets. The government initiatives recommended here, such as affordable financing options and rebate programs, require an in-depth analysis across the entire housing stock in all vintages and classifications (including new builds), to determine where best to provide financial stimulation. If such programs are well informed, government funds can be allocated in the most efficient manner for maximum GHG reductions. EPC's were also recommended to increase consumer awareness and transform the housing market to more appropriately value energy efficiency. Perhaps the most effective recommendation made here would be the realization of carbon pricing within the province because it internalizes the social costs of carbon into energy conservation economics and would allow the building industry to respond in the most flexible, and possibly, the most efficient manner.

\section{Acknowledgements}

The authors gratefully acknowledge the funding provided by the Neil B. Hutcheon Bequest. 


\section{Reference List}

[1] Ontario Ministry of the Environment, "Climate vision: climate change progress report," 2012. [Online]. Available:

http://www.ene.gov.on.ca/stdprodconsume/groups/Ir/@ene/@resources/documents/resource/stdprod_1 01103.pdf.

[2] MOE, "Policy Proposal Notice: Greenhouse Gas Emissions Reductions in Ontario: A Discussion Paper," 21 January 2013. [Online]. Available: http://www.ebr.gov.on.ca/ERS-WEB-

External/displaynoticecontent.do?noticeld=MTE4MzMy\&statusld=MTc3MDg5. [Accessed 4 February 2013].

[3] R. Galvin, "Thermal upgrades of existing homes in Germany: The building code, subsidies, and economic efficiency," Energy and Buildings, vol. 42, no. 6, pp. 834-844, 2010.

[4] J. Creyts, A. Derkach, S. Nyquist, K. Ostrowski and J. Stephenson, "Reducing U.S. greenhouse gas emissions: How much at what cost?," McKinsey \& Company, 2007.

[5] Office of Energy Efficiency , "Energy use data handbook - 1990 to 2008," Natural Resources Canada, Ottawa, 2011.

[6] Canadian Home Builders' Association, "CHBA pulse survey - Winter 2012," 2012. [Online]. Available: http://www.chba.ca/uploads/pulse\%20survey\%20results/ontario2012.pdf.

[7] Ministry of Municipal Affairs and Housing, "Supplementary standard SB-12 - Energy efficiency of housing," 2011.

[8] Lio \& Associates, "Energy efficiency measures for part 9 housing in the Ontario Building Code," Ontario Ministry of Municipal Affairs and Housing, 2006.

[9] A. Dembo, F. Khaddad and A. S. Fung, "Least-cost upgrade solutions to achieve improved energy efficiency standards for residential new housing in Canada," ASHRAE Transactions, vol. 119, no. 1, pp. 1-17, 2013.

[10] M. Dowson, A. Poole, D. Harrison and G. Susman, "Domestic Uk retrofit challenge: Barriers, incentives and current performance leading up into the Green Deal," Energy Policy, vol. 50, pp. 294-305, 2012.

[11] S. F. Gamtessa, "An explanation of residential energy-efficiency retrofit behavior in Canada," Energy and Buildings, vol. 57, pp. 155-164, 2013.

[12] Natural Resources Canada: Office of Energy Efficiency, "R-2000 Standard," 1 July 2012. [Online]. Available: http://oee.nrcan.gc.ca/residential/new-homes/r-2000/standard/16118. [Accessed 7 January 2013].

[13] L. G. Swan, V. I. Ugursal and I. Beausoleil-Morrison, "A database of house descriptions representative of the Canadian housing stock for coupling to building energy performance simulation," Journal of Building Performance Simulation, vol. 2, no. 2, pp. 75-84, June 2009. 
[14] J. Harris, "Air leakage in Ontario housing," DSG Home Inspections with Aubrey Leblanc Consulting, 2009.

[15] HVI, "HVI-Certified Products Directory," 2013. [Online]. Available: http://www.hvi.org/proddirectory/index.cfm.

[16] Natural Resources Canada, "Air-source heat pumps," 2009. [Online]. Available: http://oee.nrcan.gc.ca/publications/residential/heating-heat-pump/4608.

[17] HOT2000 v10.51 Energy Simulation Software is available from Natural Resources Canada, [Online]. Available: http://canmetenergy.nrcan.gc.ca/software-tools/hot2000/84.

[18] B. Sharp, “Ontario electricity price increase forecast," Aegent Energy Advisors Inc., 2012.

[19] U.S. Energy Information Administration, “Annual energy outlook 2013 early release overview,” 2012.

[20] Environment Canada, "National climate data and information archive," 2013. [Online]. Available: http://climate.weatheroffice.gc.ca/climateData/canada_e.html. [Accessed 17 February 2012].

[21] M. Touchie, K. D. Pressnail and C. Binkley, "Energy retrofit opportunities for mult-unit residential buildings in the city of Toronto," 2013. [Online]. Available:

http://www.towerwise.ca/files/TAF\%20MURB\%20Energy\%20Performance\%20Report,\%20Phase\%20III.pdf.

[22] Toronto Atmospheric Fund, "Emissions Quantification," [Online]. Available:

http://www.toronto.ca/taf/quant_policy_approach.htm. [Accessed 26 January 2013].

[23] Ontario Ministry of the Environment, "Climate vision: climate change progress report (technical appendix)," 2012. [Online]. Available:

http://www.ene.gov.on.ca/stdprodconsume/groups/Ir/@ene/@resources/documents/resource/stdprod_1 00824.pdf.

[24] Statistics Canada, "Focus on geography series, 2011 census - Focus on Ontario," 15 January 2013. [Online]. Available: http://www12.statcan.gc.ca/census-recensement/2011/as-sa/fogs-spg/Facts-pr-. [Accessed 25 March 2013].

[25] European Union, "Directive 2002/91/EC of the European Parliament and of the Council of 16 December 2002 on the energy performance of buildings.," 1 April 2003. [Online]. Available: http://eurlex.europa.eu/LexUriServ/LexUriServ.do?uri=OJ:L:2003:001:0065:0065:EN:PDF.

[26] Lawrence Berkeley National Laboratory, "The value of energy performance and green attributes in buildings: a review of existing literature and recommendations for future research," 7 September 2011. [Online]. Available: http://eetd.Ibl.gov/ea/emp/reports/ee-policybrief_090711.pdf.

[27] L. Laine, "Easy as EPC? Consumer views on the content and format of the energy performance certificate," June 2011. [Online]. Available: http://www.consumerfocus.org.uk/files/2011/06/Easy-as-EPC-WEB.pdf. [Accessed 22 March 2013]. 
[28] International Energy Agency, "Energy performance certification of buildings," 2010. [Online]. Available: http://www.iea.org/publications/freepublications/publication/buildings_certification-1.pdf.

[29] J. Rosenow and R. Galvin, "Evaluating the evaluations: Evidence from energy efficiency programmes in Germany and the UK," Energy and Buildings, vol. 62, pp. 450-458, 2013.

[30] H. Hens, W. Parijs and M. Deurinck, "Energy consumption for heating and rebound effects," Energy and Buildings, vol. 42, pp. 105-110, 2010.

[31] Canada Mortgage and Housing Corporation, "Green Home," CMHC, 2013.

[32] Bank of Montreal, "BMO eco smart mortgage checklist for single family homes (including townhouses)," BMO.

[33] HomePerformance, "Canada Renovation Grants," [Online]. Available: http://www.homeperformance.com/government-grants-rebates-ontario-bc-government-canada. [Accessed 12 April 2013].

[34] B. Bosquet, "Environmental tax reform: does it work? A survey of the," Ecological Economics, vol. 34, no. 1, pp. 19-32, 2000.

[35] The Economist, "British Columbia's carbon tax woos sceptics," 2011. [Online]. Available: http://www.economist.com/node/18989175. [Accessed 12 July 2013]. 